\title{
Short communication: Free fatty acid receptors FFAR1 and FFAR2 during the peripartal period in liver of dairy cows grouped by their postpartum plasma $\beta$-hydroxybutyrate concentrations
}

\author{
M. A. Aguinaga Casañas, ${ }^{*}$ C. T. Schäff, ${ }^{*}$ E. Albrecht, $†$ H. M. Hammon, ${ }^{*}$ B. Kuhla, ${ }^{*}$ M. Röntgen,† G. Nürnberg,‡ \\ and M. Mielenz ${ }^{* 1}$ \\ *Institute of Nutritional Physiology "Oskar Kellner," \\ †Institute of Muscle Biology and Growth, and \\ fInstitute of Genetics and Biometry, Leibniz Institute for Farm Animal Biology (FBN), Wilhelm-Stahl-Allee 2, 18196 Dummerstorf, Germany
}

\section{ABSTRACT}

Free fatty acid receptors (FFAR) play significant roles in various physiological processes, including energy metabolism, through interaction with their ligands, fatty acids. To determine whether the receptors FFAR1 and FFAR2 are involved in the regulation of liver metabolism during the peripartal period, we selected 13 German Holstein multiparous dairy cows and grouped them as high $\beta$-hydroxybutyrate (H-BHB; $\mathrm{n}=8$ ) or low $\beta$-hydroxybutyrate (L-BHB; $\mathrm{n}=5$ ) according to their individual maximum plasma BHB concentration observed within wk 2 or 3 postpartum (H-BHB: $>1$ $\mathrm{mmol} / \mathrm{L}$ and L-BHB: $<0.77 \mathrm{mmol} / \mathrm{L})$. The selected cows had a milk yield of more than $10,000 \mathrm{~kg} / 305 \mathrm{~d}$ during a previous lactation. The cows were fed a total mixed ration according to their requirements during the far-off dry period [5.9 MJ of net energy for lactation $\left(\mathrm{NE}_{\mathrm{L}}\right) / \mathrm{kg}$ of dry matter $(\mathrm{DM})$, crude protein $(\mathrm{CP}) 126$ $\mathrm{g} / \mathrm{kg}$ of $\mathrm{DM}]$, close-up dry period (6.5 $\mathrm{MJ}$ of $\mathrm{NE}_{\mathrm{L}} / \mathrm{kg}$ of DM, CP $137 \mathrm{~g} / \mathrm{kg}$ of DM), and lactation (7 MJ of $\mathrm{NE}_{\mathrm{L}} / \mathrm{kg}$ of DM, CP $163 \mathrm{~g} / \mathrm{kg}$ of DM). Blood samples were taken weekly, from $\mathrm{d}-34$ to $\mathrm{d} 40$ relative to parturition. Liver biopsies were taken on d $-34,-17,3$, 18 , and 30 relative to parturition and at slaughter (d 40). The protein abundance of FFAR1 was lower during the whole peripartal period in the $\mathrm{H}-\mathrm{BHB}$ group. The abundance of FFAR2 increased over time and tended to be higher in H-BHB cows. The abundance of FFAR1 might be associated with imbalances of liver metabolism in peripartal dairy cows.

Key words: free fatty acid receptors, liver, dairy cow, $\beta$-hydroxybutyrate

Received February 11, 2016.

Accepted December 8, 2016.

${ }^{1}$ Corresponding author: mielenz@fbn-dummerstorf.de

\section{Short Communication}

Free fatty acid receptors (FFAR) play significant roles in energy metabolism (Brown et al., 2005; Ichimura et al., 2009). The receptor FFAR1 is involved in insulin secretion in humans (Meidute Abaraviciene et al., 2013). Activation of the receptor FFAR2 increases lipid accretion and reduces lipolysis in mice (Hong et al., 2005). Short-chain fatty acids activate FFAR2, whereas medium- and long-chain fatty acids are ligands for FFAR1 (Brown et al., 2003; Kim et al., 2013; Yonezawa et al., 2013). Functionalities of bovine FFAR1 and FFAR2 have been demonstrated. Initially, Wang et al. (2009) showed decreasing acetate-, propionate-, and butyrate-activated cyclic AMP using bovine FFAR2-transfected Chinese hamster ovary (CHO) cells. Hudson et al. (2012) established pharmacological differences between human and bovine FFAR2; for example, by using the extracellular signal-regulated kinase $1 / 2$ phosphorylation assay. Manosalva et al. (2015) cloned and characterized bovine FFAR1 by measuring intracellular calcium levels after receptor activation and demonstrated effects of receptor activation on production of bovine neutrophil reactive oxygen species. Friedrichs et al. (2014) observed the greatest mRNA abundance of FFAR1 in liver compared with other tissues, which decreased after parturition. The mRNA of FFAR2 in liver, which is not regulated during the peripartal period, is higher compared with that in muscle but comparable to that in subcutaneous adipose tissue. Protein data on both receptors in bovine liver is not available yet. Because of the general association of FFAR1 and FFAR2 with energy metabolism in other species, the ubiquitous importance of the signal transduction pathways used by these receptors, and the importance of their ligands for bovine liver metabolism, we hypothesize that both receptors could be involved in the regulation of liver metabolism of dairy cows during the peripartal period. The increasing synthesis of $\mathrm{BHB}$ postpartum is driven by increasing fatty acid 
concentrations but also by other intermediates such as lactate and ketogenic amino acids and could be related to individual differences in the gluconeogenic capacity with propionate as main precursor for gluconeogenesis, as discussed by McCarthy et al. (2015a). High concentrations of $\mathrm{BHB}$ postpartum are related to changes in the abundance of enzymes linked to the reduction of hepatic $\beta$-oxidation in bovine liver (Li et al., 2012). Simultaneously, with increasing ketone body formation and fatty acid concentrations, the gluconeogenic activity of the liver is decreased (Grummer, 1993; McCarthy et al., 2015b). A higher prevalence of subclinical ketosis is observed when BHB exceeds $1.2 \mathrm{mmol} / \mathrm{L}$ postpartum (Suthar et al., 2013).

For the current study, cows with different capabilities of metabolic adaptation to the transition period, based on their plasma BHB concentrations postpartum, were used to determine whether a relationship with FFAR1 or FFAR2 exists in the bovine liver.

Thirteen multiparous German Holstein cows, in their second to fourth lactation, were selected from a previous study (Schäff et al., 2012) based on their individual peak in plasma BHB concentrations in wk 2 or 3 postpartum: high BHB (H-BHB; 1.05 to 2.57 $\mathrm{mmol} / \mathrm{L}$, mean $1.59 \mathrm{mmol} / \mathrm{L} ; \mathrm{n}=8)$ and low $\mathrm{BHB}$ (L-BHB; 0.43 to $0.76 \mathrm{mmol} / \mathrm{L}$, mean $0.65 \mathrm{mmol} / \mathrm{L}$; n $=5)$ concentrations. The cows had a milk yield of more than $10,000 \mathrm{~kg} / 305 \mathrm{~d}$ in a previous lactation, and were selected according to their DGAT1 genotype (K232A) to exclude differences in fat metabolism based on this trait. Cows were housed in tiestalls and were fed twice daily (0630 and 1530 h) 1 of 3 different TMR (Supplemental Table S1 for further information on the diet; https://doi.org/10.3168/jds.2016-11021) corresponding to their physiological state; that is, far-off dry period (wk 7 to 4 before expected calving; $5.9 \mathrm{MJ}$ of $\mathrm{NE}_{\mathrm{L}} / \mathrm{kg}$ of DM; CP $126 \mathrm{~g} / \mathrm{kg}$ of DM), close-up dry period (wk 3 until calving; $6.5 \mathrm{MJ}$ of $\mathrm{NE}_{\mathrm{L}} / \mathrm{kg}$ of $\mathrm{DM}$; CP $137 \mathrm{~g} /$ $\mathrm{kg}$ of $\mathrm{DM}$ ), and lactation (7 MJ of $\mathrm{NE}_{\mathrm{L}} / \mathrm{kg}$ of DM; CP $163 \mathrm{~g} / \mathrm{kg}$ of DM) according to the recommendations of German Society of Nutritional Physiology (GfE, 2001).

All procedures were conducted in agreement with the recommendations for the use of animals as experimental subjects of the State Government in MecklenburgWest Pomerania (Registration No. LALLF M-V/ TSD/7221.3-2.1-021/09). Blood samples were taken weekly, starting at $\mathrm{d}-34$ relative to parturition until slaughter at d 40, from the jugular vein into EDTAcontaining tubes (no. 4550036; Greiner Bio-One, Frickenhausen, Germany) and centrifuged at 1,565 $\times g$ for $20 \mathrm{~min}$ at $4^{\circ} \mathrm{C}$. The obtained plasma was stored at $-80^{\circ} \mathrm{C}$ until analyzed. Liver tissue samples were taken by biopsy at $\mathrm{d}-34,-17,3,18$, and 30 relative to parturition and by sampling at slaughter (d 40). Tissue obtained was immediately frozen and stored at $-80^{\circ} \mathrm{C}$ for further analysis. Further details on animal management and samples collection, including data on BHB concentrations and energy balance, were published by Schäff et al. (2012, 2013). Data on protein extraction, SDS-PAGE, Western blotting, and immunohistochemistry are provided as supplemental data (https://doi. org/10.3168/jds.2016-11021).

All data were analyzed using SAS software (version 9.3, SAS Institute Inc., Cary, NC). Because of very low FFAR1 protein detection (at the detection limit or no signal) in $3 \mathrm{H}-\mathrm{BHB}$ cows, quantification was not possible within a linear range and therefore these animals were omitted from the statistical analysis (H-BHB: $\mathrm{n}=$ 5; L-BHB $\mathrm{n}=5$ ). The MIXED procedure of SAS for repeated measures was used, considering group, time, and their interactions as fixed effects. As covariance structures the spatial power or ante-dependence were used. The Tukey-Kramer test was applied for multiple comparisons of means. In addition, Spearman correlation statistics with Fisher's z transformations for the calculation of the $95 \%$ confidence limits were calculated for FFAR1 and FFAR2 versus blood metabolites and the liver fat content (LFC) without grouping by BHB. Statistical significance was accepted at $P<0.05$ and trends toward significances were considered at $P<0.10$.

The analysis of FFAR1 and FFAR2 in liver revealed specific protein bands of $\sim 31$ and $50 \mathrm{kDa}$, respectively. The use of antigen-specific blocking peptides confirmed the specificity of both antibodies (Supplemental Figure S1; https://doi.org/10.3168/jds.2016-11021). As shown in Figure 1A, H-BHB animals had lower hepatic FFAR1 abundance $(P=0.011)$ than L-BHB cows over the entire peripartal period. Changes over time were observed as a trend $(P=0.096)$. In contrast, abundance of FFAR2 protein tended to be higher in H-BHB cows than in L-BHB cows (Figure 1B; $P=0.055$ ). In addition, the abundance of FFAR2 increased over time (Figure 1B; $P$ $=0.025)$. No interactions between group and time were found for either protein. The calculation of the correlations revealed a positive correlation of FFAR1 with plasma glucose concentrations antepartum $(\mathrm{r}=0.68, P$ $=0.004)$ as well as postpartum $(\mathrm{r}=0.49, P=0.009)$ but negative correlations with $\mathrm{BHB}$ postpartum $(\mathrm{r}=$ $-0.46, P=0.016)$ and LFC $(\mathrm{r}=-0.40, P=0.040)$. In contrast, FFAR2 was correlated negatively with glucose postpartum $(\mathrm{r}=-3.5, P=0.041)$ but positively correlated with BHB ( $\mathrm{r}=0.52, P=0.001$; Supplemental Table S2; https://doi.org/10.3168/jds.2016-11021). For further information on blood metabolites, insulin, LFC as well as energy balance, please check Supplemental Table S3 (https://doi.org/10.3168/jds.2016-11021).

Immunohistochemistry using anti-FFAR 1 antibodies revealed immunoreactivity for FFAR1 in association 

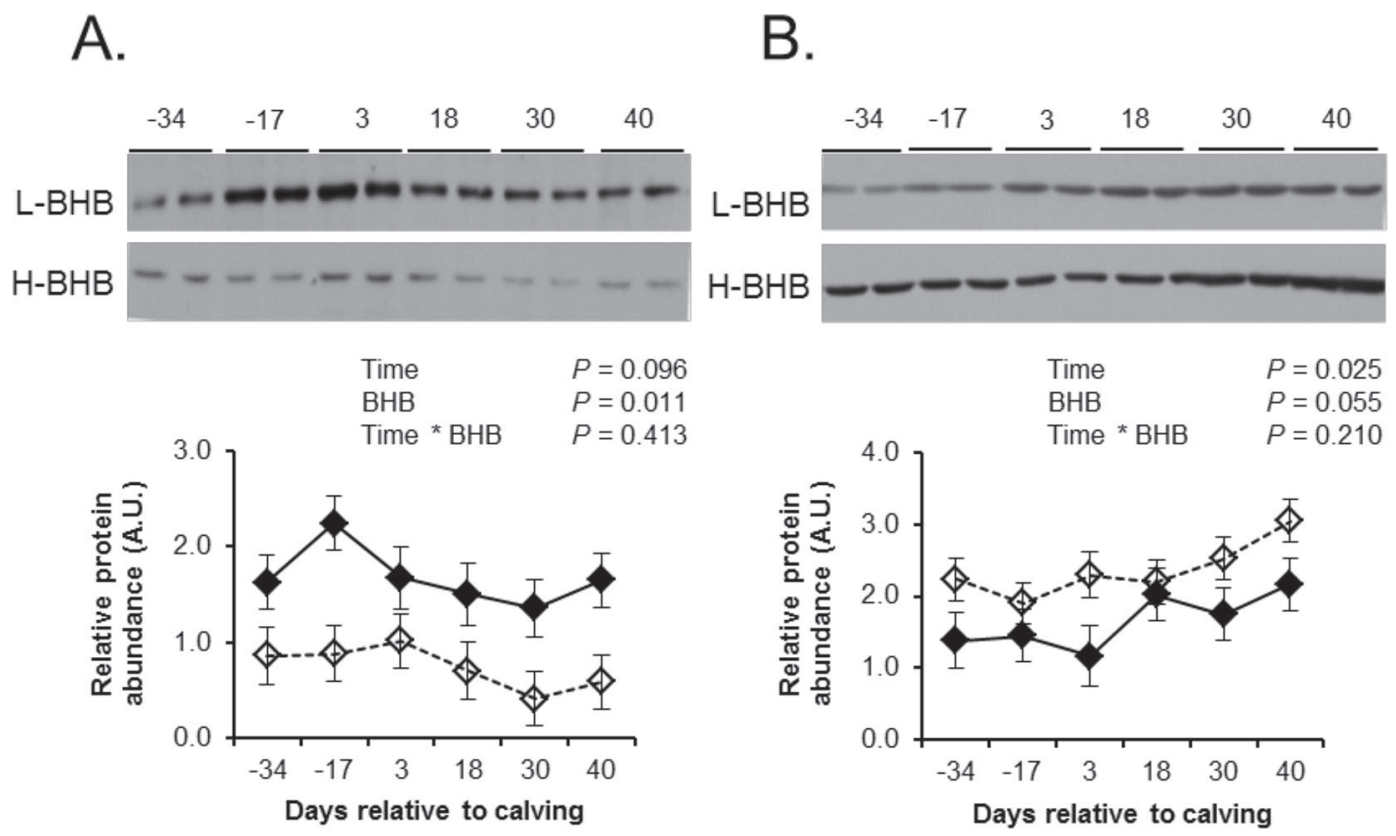

Figure 1. Abundance (expressed as arbitrary units, A.U.; LSM \pm SE) of free fatty acid receptors FFAR1 (A) and FFAR2 (B) during the transition period (d -35 to d 40 relative to parturition) of dairy cows grouped, by their maximum BHB concentrations 2 to 3 wk postpartum, as having high (H-BHB, $\diamond ; \mathrm{n}=5$ ) or low (L-BHB, $\diamond ; \mathrm{n}=5$ ) BHB concentration.

with the cell membrane of the hepatocytes (Figure 2). However, the anti-FFAR2 antibody was not suitable for immunohistochemistry under the tested conditions (data not shown).

Fatty liver is an important metabolic disorder after partition in dairy cows. This metabolic disease is strongly associated with the formation of BHB as an indicator for elevated LFC as a result of increasing plasma fatty acid concentrations, as reviewed by Bobe et al. (2004). In addition, increasing concentrations of BHB are associated with decreasing glucose synthesis (Grummer, 1993), and individual differences in gluconeogenic capacity could be involved, as discussed by McCarthy et al. (2015a). By using BHB concentrations to group animals in the current study, metabolic pathways were covered, which are associated with the ligand spectrum of FFAR1 and FFAR2 (Brown et al., 2003; Kim et al., 2013; Yonezawa et al., 2013). The grouping of our cows by maximum BHB concentrations was more successful compared with fatty acid concentrations because of less individual fluctuations of BHB concentrations postpartum (data not shown). Very large variations on the day of maximum BHB but also fatty acid concentrations postpartum were found by McCarthy et al. (2015a); however, as observed in that study, the postpartum BHB area under the curve concentrations were less variable than the fatty acid concentrations. By our grouping, only plasma glucose concentrations and plasma cholesterol concentrations (trend) were lower, in contrast to fatty acids and LFC, which were numerically higher in H-BHB cows on d 18 and 30 postpartum.

The effects of FFAR1 and FFAR2 activation in different tissues have been reported in several species (Hara et al., 2014). Herein, we report the first evidence for differential expression of FFAR1 and FFAR2 during the peripartal period in the liver of dairy cows that differ in liver metabolism, based on BHB measurement after calving. Our observations regarding the time periods are at least partly in line with Börner et al. (2013). In that study, based on the same animals as used in the study of Schäff et al. (2012), it was observed that cows with more lipid mobilization postpartum showed lower carbohydrate oxidation and higher fat oxidation postpartum but also antepartum. Comparable differences, including the antepartum and postpartum periods, were extended to mRNA levels of genes linked to lipid and carbohydrate metabolic pathways by Schäff et al. (2012), when grouping the cows by liver fat content postpartum.

It has been shown, in human HepG2 cells as well as in human primary liver cells, that oleic acid increases the expression of FFAR1 and activates the receptor (Wu et al., 2012). This activation is indirectly linked to improved insulin sensitivity and increased $\beta$-oxidation and involves the activation of peroxisome proliferatoractivated receptor $\delta$ (PPAR $\delta$ ) through the FFAR1phospholipase $\mathrm{C}$-calcium pathway, as demonstrated in 
humans and rats. In detail, the increased abundance of PPAR $\delta$ by increased FFAR1 expression was negatively associated with abundance of phosphatase and tensin homolog (PTEN), which blocks phosphorylation of insulin-dependent serine/threonine protein kinase Akt/PKB. Consequently, the expression of PPAR $\delta$ by FFAR1 activation improves insulin sensitivity in steatotic cells (Wu et al., 2012). However, it is important to note that differences in liver lipid metabolism between rodents and ruminants exist. For example, in contrast to human or mouse and using glucose as precursor for de novo fatty acid synthesis, the rate of de novo lipogenesis in the liver of ruminants, using mainly acetate as precursor, is low. In addition, the hepatic capacity to esterify fatty acids taken up from the bloodstream is limited (Adewuyi et al., 2005; Bergen and Mersmann, 2005). Less information is available on FFAR1 importance in the bovine. It is known that the FFAR1 agonist GW9508 is functional in the bovine (Manosalva et al., 2015). In mice, the same agonist decreases sterol regulatory element-binding protein 1 (Ou et al., 2014), and overexpression of this transcription factor in bovine hepatocytes in vitro induces triglyceride accumulation (Li et al., 2014). Therefore, because of the functionality of the FFAR1 agonist GW9508 in both species, a comparable effect of FFAR1 on bovine sterol regulatory element-binding protein 1 and thus lipid metabolism cannot be ruled out.

We detected the FFAR2 protein with a molecular mass of about $50 \mathrm{kDa}$, which is comparable to the main band detected in pigs ( $\mathrm{Li}$ et al., 2014) but different from the calculated size based on the sequence (Wang et al., 2009). The size difference can be explained, at least in part, by glycosylation sites, which are predicted by the NetNGlyc 1.0 server (http://www.cbs.dtu.dk, $2015 / 11 / 17)$, and the specificity was confirmed by the specific blocking peptide. The abundance of FFAR2 protein increased over time during the peripartal pe-

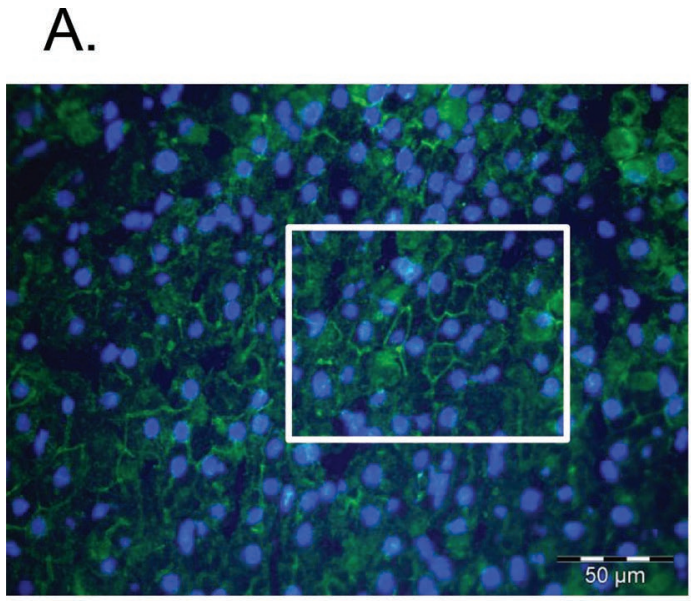

\section{B.}
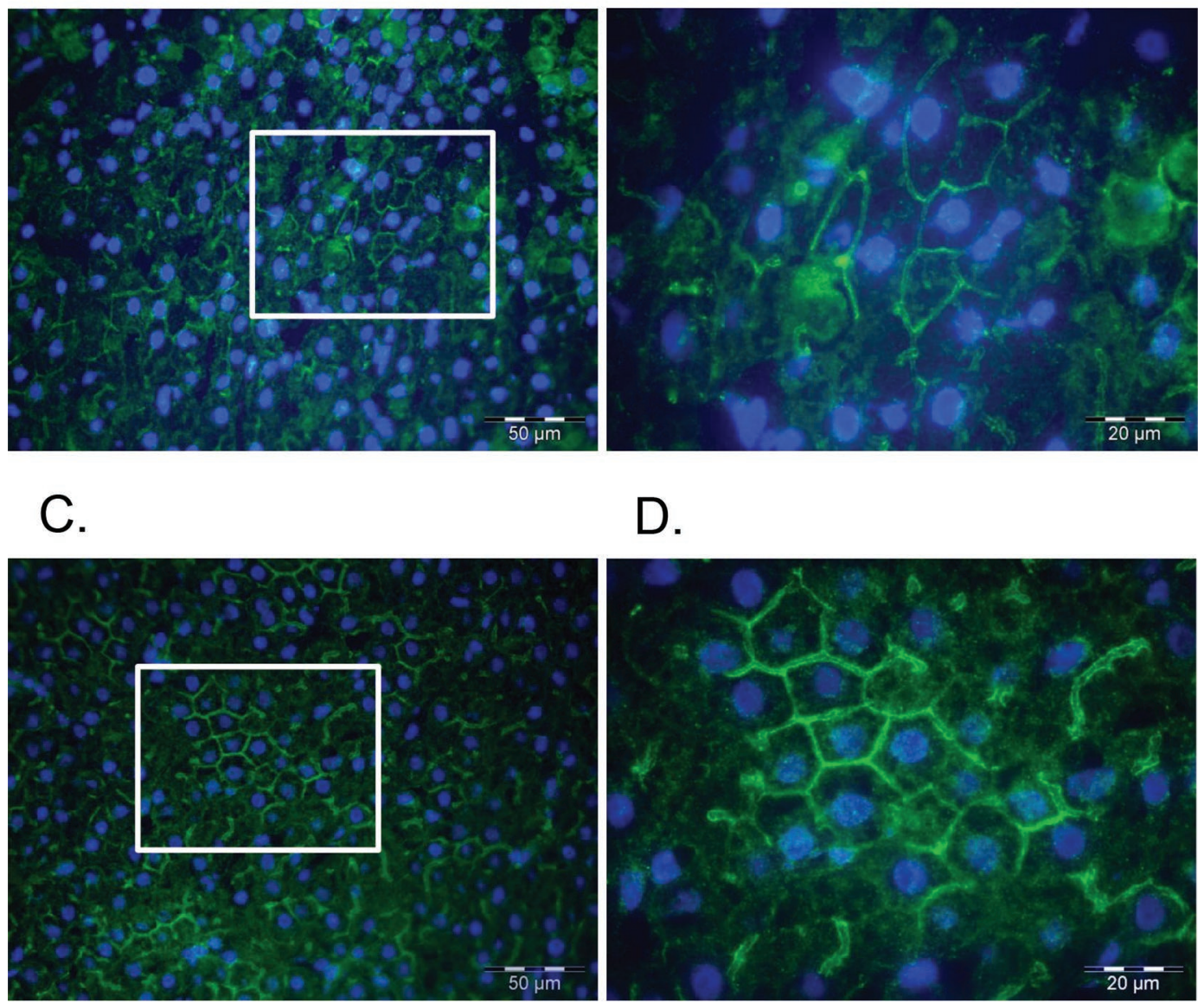

Figure 2. Demonstration of free fatty acid receptor 1 (FFAR1) protein in liver of dairy cows by immunohistochemistry, showing the presence of FFAR1 (green) in the cell membrane of bovine hepatocytes in 2 animals (A, C); nuclei were counterstained with Hoechst 33258 (blue). The inset squares in panels $\mathrm{A}$ and $\mathrm{C}$ are shown magnified in panels $\mathrm{B}$ and $\mathrm{D}$, respectively. Color version available online. 
riod. However, Friedrichs et al. (2014) did not find any changes in the expression of FFAR2 mRNA in the liver of dairy cows during the peripartal period.

Bovine FFAR2 has a lower affinity for acetate and propionate than human FFAR2 (Hudson et al., 2012). Despite this, the concentration of propionate and butyrate in the portal vein (Lomax and Baird, 1983; Casse et al., 1994; Benson et al., 2002) reaches the halfmaximal effective concentration (EC50) to activate the receptor, respectively. The portal vein concentrations indicate that the percentage of activation of this receptor in liver might be higher than its activation in other bovine tissues such as adipose tissue, because of lesser blood concentrations of butyrate and propionate in the periphery because of their percentage of hepatic extraction. However, the physiological significance of this receptor for liver metabolism has not been studied previously. Based on the number of animals in the current study, the correlation analysis may not be meaningful. However, it supports the decision to group by BHB level and reveals possibly contrasting associations of the two receptors with metabolic regulation during the peripartal period.

In conclusion, we detected higher abundance of FFAR1 in animals with lower postpartum plasma BHB concentrations. In contrast, the abundance of FFAR2 was lower (a trend) in animals with lower BHB but increased over time. The physiological significance of these observations should be investigated in future studies.

\section{ACKNOWLEDGMENTS}

We thank A.-K. Möller, the staff at the FBN cattle facility, and the "Tiertechnikum" for help with the analyses and animal care, as well G. Das and A. Tuchscherer for discussion on the statistical analyses. We gratefully acknowledge S. Börner, S. Hacke, and U. Kautzsch for their help in collecting the samples (all of FBN Dummerstorf). We thank Rupert Bruckmaier (Veterinary Physiology, Vetsuisse Faculty, University of Bern, Switzerland) for the measurement of insulin. We acknowledge the help of the Cattle Breeding Organization Mecklenburg-West Pommerania (RMV) and the Griepentrog farm for the assortment of cows. This study is based on an animal model that was supported by Deutsche Forschungsgemeinschaft (DFG; Bonn, Germany; KU 1956/4-1, HA 4372/7-1).

\section{REFERENCES}

Adewuyi, A. A., E. Gruys, and F. J. van Eerdenburg. 2005. Nonesterified fatty acids (NEFA) in dairy cattle. A review. Vet. Q. $27: 117-126$.
Benson, J. A., C. K. Reynolds, P. C. Aikman, B. Lupoli, and D. E. Beever. 2002. Effects of abomasal vegetable oil infusion on splanchnic nutrient metabolism in lactating dairy cows. J. Dairy Sci. 85:1804-1814.

Bergen, W. G., and H. J. Mersmann. 2005. Comparative aspects of lipid metabolism: Impact on contemporary research and use of animal models. J. Nutr. 135:2499-2502.

Bobe, G., J. W. Young, and D. C. Beitz. 2004. Invited review: Pathology, etiology, prevention, and treatment of fatty liver in dairy cows. J. Dairy Sci. 87:3105-3124.

Börner, S., E. Albrecht, C. Schäff, S. Hacke, U. Kautzsch. M. Derno, H. M. Hammon, M. Rontgen, H. Sauerwein, and B. Kuhla. 2013. Reduced AgRP activation in the hypothalamus of cows with high extent of fat mobilization after parturition. Gen. Comp. Endocrinol. 193:167-177.

Brown, A. J., S. M. Goldsworthy, A. A. Barnes, M. M. Eilert, L. Tcheang, D. Daniels, A. I. Muir, M. J. Wigglesworth, I. Kinghorn, N. J. Fraser, N. B. Pike, J. C. Strum, K. M. Steplewski, P. R. Murdock, J. C. Holder, F. H. Marshall, P. G. Szekeres, S. Wilson, D. M. Ignar, S. M. Foord, A. Wise, and S. J. Dowell. 2003. The Orphan G protein-coupled receptors GPR41 and GPR43 are activated by propionate and other short chain carboxylic acids. J. Biol. Chem. 278:11312-11319.

Brown, A. J., S. Jupe, and C. P. Briscoe. 2005. A family of fatty acid binding receptors. DNA Cell Biol. 24:54-61.

Casse, E. A., H. Rulquin, and G. B. Huntington. 1994. Effect of mesenteric vein infusion of propionate on splanchnic metabolism in primiparous Holstein cows. J. Dairy Sci. 77:3296-3303.

Friedrichs, P., B. Saremi, S. Winand, J. Rehage, S. Danicke, H. Sauerwein, and M. Mielenz. 2014. Energy and metabolic sensing G protein-coupled receptors during lactation-induced changes in energy balance. Domest. Anim. Endocrinol. 48:33-41.

GfE (German Society of Nutrition Physiology). 2001. Recommended energy and nutrient supply for dairy cows and growing cattle. DLG-Verlag, Frankfurt am Main, Germany.

Grummer, R. R. 1993. Etiology of lipid-related metabolic disorders in periparturient dairy cows. J. Dairy Sci. 76:3882-3896.

Hara, T., D. Kashihara, A. Ichimura, I. Kimura, G. Tsujimoto, and A. Hirasawa. 2014. Role of free fatty acid receptors in the regulation of energy metabolism. Biochim. Biophys. Acta 1841:1292-1300.

Hong, Y. H., Y. Nishimura, D. Hishikawa, H. Tsuzuki, H. Miyahara, C. Gotoh, K. C. Choi, D. D. Feng, C. Chen, H. G. Lee, K. Katoh, S. G. Roh, and S. Sasaki. 2005. Acetate and propionate short chain fatty acids stimulate adipogenesis via GPCR43. Endocrinology 146:5092-5099.

Hudson, B. D., E. Christiansen, I. G. Tikhonova, M. Grundmann, E. Kostenis, D. R. Adams, T. Ulven, and G. Milligan. 2012. Chemically engineering ligand selectivity at the free fatty acid receptor 2 based on pharmacological variation between species orthologs. FASEB J. 26:4951-4965.

Ichimura, A., A. Hirasawa, T. Hara, and G. Tsujimoto. 2009. Free fatty acid receptors act as nutrient sensors to regulate energy homeostasis. Prostaglandins Other Lipid Mediat. 89:82-88.

Kim, M. H., S. G. Kang, J. H. Park, M. Yanagisawa, and C. H. Kim. 2013. Short-chain fatty acids activate GPR41 and GPR43 on intestinal epithelial cells to promote inflammatory responses in mice. Gastroenterology 145:396-406.

Li, G., H. Su, Z. Zhou, and W. Yao. 2014. Identification of the porcine $\mathrm{G}$ protein-coupled receptor 41 and 43 genes and their expression pattern in different tissues and development stages. PLoS One 9:e97342.

Li, X., X. Li, G. Bai, H. Chen, Q. Deng, Z. Liu, L. Zhang, G. Liu, and Z. Wang. 2012. Effects of non-esterified fatty acids on the gluconeogenesis in bovine hepatocytes. Mol. Cell. Biochem. 359:385-388.

Lomax, M. A., and G. D. Baird. 1983. Blood flow and nutrient exchange across the liver and gut of the dairy cow. Effects of lactation and fasting. Br. J. Nutr. 49:481-496.

Manosalva, C., J. Mena, Z. Velasquez, C. K. Colenso, S. Brauchi, R. A. Burgos, and M. A. Hidalgo. 2015. Cloning, identification and functional characterization of bovine free fatty acid receptor-1 (FFAR1/GPR40) in neutrophils. PLoS One 10:e0119715. 
McCarthy, M. M., S. Mann, D. V. Nydam, T. R. Overton, and J. A. McArt. 2015a. Short communication: Concentrations of nonesterified fatty acids and beta-hydroxybutyrate in dairy cows are not well correlated during the transition period. J. Dairy Sci. 98:62846290.

McCarthy, M. M., M. S. Piepenbrink, and T. R. Overton. 2015b. Associations between hepatic metabolism of propionate and palmitate in liver slices from transition dairy cows. J. Dairy Sci. 98:70157024 .

Meidute Abaraviciene, S., S. J. Muhammed, S. Amisten, I. Lundquist, and A. Salehi. 2013. GPR40 protein levels are crucial to the regulation of stimulated hormone secretion in pancreatic islets. Lessons from spontaneous obesity-prone and non-obese type 2 diabetes in rats. Mol. Cell. Endocrinol. 381:150-159.

Ou, H. Y., H. T. Wu, F. H. Lu, Y. C. Su, H. C. Hung, J. S. Wu, Y. C. Yang, C. L. Wu, and C. J. Chang. 2014. Activation of free fatty acid receptor 1 improves hepatic steatosis through a p38dependent pathway. J. Mol. Endocrinol. 53:165-174.

Schäff, C., S. Börner, S. Hacke, U. Kautzsch, D. Albrecht, H. M. Hammon, M. Röntgen, and B. Kuhla. 2012. Increased anaplerosis, TCA cycling, and oxidative phosphorylation in the liver of dairy cows with intensive body fat mobilization during early lactation. J. Proteome Res. 11:5503-5514.

Schäff, C., S. Börner, S. Hacke, U. Kautzsch, H. Sauerwein, S. K. Spachmann, M. Schweigel-Röntgen, H. M. Hammon, and B. Kuhla. 2013. Increased muscle fatty acid oxidation in dairy cows with intensive body fat mobilization during early lactation. J. Dairy Sci. 96:6449-6460.

Suthar, V. S., J. Canelas-Raposo, A. Deniz, and W. Heuwieser. 2013. Prevalence of subclinical ketosis and relationships with postpartum diseases in European dairy cows. J. Dairy Sci. 96:2925-2938.

Wang, A., Z. Gu, B. Heid, R. M. Akers, and H. Jiang. 2009. Identification and characterization of the bovine $\mathrm{G}$ protein-coupled receptor GPR41 and GPR43 genes. J. Dairy Sci. 92:2696-2705.

Wu, H. T., W. Chen, K. C. Cheng, P. M. Ku, C. H. Yeh, and J. T. Cheng. 2012. Oleic acid activates peroxisome proliferator-activated receptor delta to compensate insulin resistance in steatotic cells. J. Nutr. Biochem. 23:1264-1270.

Yonezawa, T., R. Kurata, K. Yoshida, M. A. Murayama, X. Cui, and A. Hasegawa. 2013. Free fatty acids-sensing G protein-coupled receptors in drug targeting and therapeutics. Curr. Med. Chem. 20:3855-3871. 